\title{
Practices, Challenges and Perceived Influence of Classroom Assessment on Mathematics Instruction
}

\author{
Isaac Buabeng (iD 1, ${ }^{*}$, Amoah Barnabas Atingane ${ }^{2}$, Isaac Amoako ${ }^{3}$ \\ ${ }^{1,2}$ Department of Basic Education, University of Cape Coast, Ghana \\ ${ }^{3}$ Department of Education and Psychology, University of Cape Coast, Ghana
}

\section{ARTICLE HISTORY}

Received: 20 March 2019

Revised: 07 August 2019

Accepted: 22 August 2019

\section{KEYWORDS}

Classroom Assessment, Instruction,

Feedback,

Assessment Practices, Mathematics Teachers, Junior High School

\begin{abstract}
Assessment is a powerful tool for raising the standards of teaching and learning of mathematics at the junior high school level. This study therefore explored the perceived influence of assessment on the teaching and learning of mathematics in junior high schools of OLA Circuit in Cape Coast Metropolitan area. The research design used for the study is a concurrent triangulation mixed method design. A simple random sampling technique was used to select four (4) public junior high schools out of eight (8) schools in the circuit. A multistage sampling procedure was employed to select the schools and participants for the study. A total of 134 participants comprising 15 teachers and 119 students participated in the study. The data for the study were mainly collected through questionnaires and interviews. Findings of the study revealed that class exercise, homework, and trial work were the most common mode of assessment used by teachers during mathematics instruction. Again, the study discovered that teachers faced some challenges in the implementation of classroom assessment. The study therefore makes certain recommendations likely to improve on the quality of assessment practices in mathematics classrooms in the focal schools.
\end{abstract}

\section{INTRODUCTION}

The essential purpose of education is to help the individual to be able to use their learning and their own mind as the anvil for creating new ideas, processes, gadgets and appliances (Curriculum Research and Development Division [CRDD], 2011). Mathematics is one of the essential areas of learning. According to the CRDD (2012),

' 'today's world demands that young people should be able to use numbers competently, read and interpret numeral data, reason logically, as well as communicate effectively with other people using accurate mathematical data and interpretations" (p. 3).

It is due to this that mathematics has been considered as one of the core subjects in the basic and the second cycle school curriculums in Ghana. However, the teaching and learning of mathematics at the Junior High School (JHS) level cannot be meaningful if students are taught only to repeat what is taught in school without giving them the opportunity to engage in critical

CONTACT: Isaac Buabeng $₫$ ibuabeng@ucc.edu.gh Department of Basic Education, University of Cape Coast, Ghana 
productive thinking and application of their knowledge to variety of situations while they are still in school.

For example, available statistics from the Cape Coast Metropolitan Education Directorate show that students' performance in mathematics is relatively low as compared to the other core subjects. For example, in 2010, the number of registered candidates who obtained passes (grades 1- 6) in mathematics in the Basic Education Certificate Examination (BECE) in the Metropolis was $36.7 \%$ as compared to $60.3 \%, 47.9 \%$ and $52.4 \%$ for English Language, Integrated Science and Social Studies respectively (Cape Coast Metropolitan Education Directorate, 2010). Similarly, in 2012, there was 40\% number of candidates who obtained passes (grades $1-6$ ) in Mathematics in the BECE as against $62 \%, 41 \%$ and $49 \%$ for English Language, Integrated Science and Social Studies respectively (Cape Coast Metropolitan Education Directorate, 2012). Again, in 2014, 60.95\% number of candidates obtained passes (grades $1-6$ ) in Mathematics in the BECE as compared to $76.36 \%, 70.49 \%$ and $62.88 \%$ for English Language, Integrated Science and Social Studies respectively (Cape Coast Metropolitan Education Directorate, 2014).

A careful look at the statistics above indicates that, students' performance of mathematics has been increasing over the years, however, the rate of increment is not substantial in comparison with the other core subjects such as integrated science, social studies and English. It has been argued that formative assessment practices serve the purpose of improving classroom instruction with subsequent effect on enhancing performance (Amoako, 2018). Also, it is expected that school-based assessment with particular emphasis on formative assessment will help teachers and pupils to achieve the objectives of the syllabus and consequently raise the standard of mathematics learning in the country (CRDD, 2011). Considering that the CRDD requires that all teachers incorporate formative assessment into their teaching due to its perceived benefits, it is curious as to why the mathematics performance of JHS students in mathematics within the Cape Coast Metropolis is not experiencing great gains. Could it be that teachers are not engaging in formative assessment practices? Or could it be due to ineffective assessment practices? In view of these and many other nagging questions, the authors investigated the kind of assessment modes (tools) and format that teachers use to drive instruction of mathematics in the area as well as any possible challenges that they face in the implementation of the various assessment procedures such as captured in the JHS mathematics syllabus. The study was guided by the following research questions:

1. What mode of assessment do JHS teachers use during mathematics instruction?

2. What format of assessment do JHS mathematics teachers frequently use?

3. What is the assessment feedback practices of mathematics teachers in OLA circuit?

4. What is the perceived influence of assessment practices on mathematics instruction in the JHS?

5. What challenges do mathematics teachers face during the implementation of assessment procedure in the classroom?

\section{METHOD}

Concurrent triangulation mixed method design was used for the study. This research strategy can be identified by its use of one data collection phase, during which both quantitative and qualitative data are collected simultaneously for the purpose of verification of information received (Creswell, 2003). For the purpose of this study, all JHSs in the Cape Coast metropolis were targeted. However, for efficiency of investigation, OLA circuit having eight (8) JHSs became the accessible population. The number of teachers within the circuit was estimated to be 70, made up of 29 males and 41 females whereas the number of students was also estimated to be 928 , made up of 398 boys and 530 girls. 
In selecting the samples, a multi-staged sampling procedure was used. At the first stage, purposive sampling procedure was used to select OLA circuit. The circuit was selected because it has most of the JHS within the Metropolis. On the second stage, random sampling method was used to select four JHSs out of a total of eight JHSs within the circuit. Using Krejcie and Morgan sampling size determination specifications (Sarantakos, 2005), a total of 119 students which was made up of 57(47.9\%) males and 62(52.1\%) females from the four randomly selected public JHSs participated in the study. Convenient sampling was also utilized to engage all the mathematics teachers from the selected schools, who were at post during the time of the study. This procedure was used to allow teachers who were ready and willing to participate in the conduct of the study to be selected. In all 15 mathematics teachers participated in the study.

Data for the study were obtained from two main sources, questionnaires for students and teachers, and interviews with teachers. The questionnaires were administered to both teachers and students while the interview was administered to the teachers. Only teachers were interviewed and not students because teachers make use of assessment procedures and hence would be able to tell how it affect instructions. The questionnaire (with overall Cronbach Alpha estimate of .72) was a four-point Likert scale with extreme responses of "Strongly Agree to Strongly Disagree." The interview guide was semi-structured in nature which allowed the researchers to explore other issues as emerged from participant's responses. The quantitative data were analyzed using mean and standard deviation whereas thematic approach was adopted for the qualitative data. Where quotes are used within the body of the results, they were chosen because they were representative of the statements by most of the respondents.

\section{RESULTS}

The results are presented as guided by the research questions which underpinned this study. In the next sections, we present the results of the research questions.

\subsection{Mode of Assessment used by Teachers}

Research question one sought to find out the mode of assessment that JHS teachers use in the classroom during mathematics instructions. Summary of the analysis is presented in Table 1.

Table 1. Teachers' Views on the Mode of Assessment that they Commonly Use $(\mathrm{N}=15)$

\begin{tabular}{lcc}
\hline Assessment Tool & Mean & SD \\
\hline Class test & 2.27 & 0.46 \\
Class exercise & 3.67 & 0.49 \\
Homework & 3.73 & 0.46 \\
Group work & 2.10 & 0.26 \\
Project work & 1.40 & 0.51 \\
Trial work during lessons & 3.53 & 0.64 \\
\hline Average scores & 2.78 & 0.47 \\
\hline Mean Range: Not used (0.4-1.4), used occasionally (1.5-2.4), used often (2.5-3.4); used very often $(3.5-4.4)$
\end{tabular}

Table 1 shows that teachers often use variety of assessment modes in the classroom to assess students' progress in mathematics. This is evident by the average mean score $(M=2.78, S D=$ .47). As shown in Table 1, class exercises $(\mathrm{M}=3.67, \mathrm{SD}=0.56)$, homework $(\mathrm{M}=3.73, \mathrm{SD}=0.46)$, and trial work $(\mathrm{M}=3.53, \mathrm{SD}=0.64)$ were the modes of assessment often used by teachers.

Most of the teachers interviewed confirmed the above results when they asserted that they use more of the class test, class exercise, homework and trial work since these tools are prescribed in the school-based assessment guide. However, most of the teachers admitted in the interview that they do not use projects and group work as expected. Two teachers commented as follows: 
I do not use project because it is not easy to find project topics for mathematics as compared to subjects like Integrated Science. [Teacher 'A']

The students don't like working in groups and when you give them group work, they rather make noise instead of doing the work. [Teacher ' $C$ ']

The second research question elicited from the students, their views about the assessment modes that are commonly used by their mathematics teachers. The results of Table 2 shows that the students held similar views as the teachers with regards to how often the named assessment modes were used in mathematics in their schools. The average mean score and standard deviation were 2.85 and 0.79 respectively. This indicates that the students view the assessment modes as 'used often' by their teachers.

Table 2. Students' Views on Assessment Modes that are Commonly used by their Teachers (N=119)

\begin{tabular}{lcc}
\hline Assessment Tool & Mean & Std. dev. \\
\hline Class test & 2.50 & 0.74 \\
Class exercise & 3.73 & 0.56 \\
Homework & 3.47 & 0.74 \\
Group work & 2.40 & 0.92 \\
Project work & 1.81 & 0.98 \\
Trial work during lessons & 3.48 & 0.72 \\
\hline Average scores & 2.85 & 0.79 \\
\hline
\end{tabular}

Mean Range: Not used (0.4-1.4), used occasionally (1.5-2.4), used often (2.5-3.4); used very often (3.5-4.4).

An examination of the individual items points to the same results as seen in Table 3. Therefore, the students share similar views as their teachers.

\subsection{Format of Assessment}

Research question two sought to investigate the commonly used assessment format by mathematics teachers in the circuit. Summary of the analysis is shown in Table 3.

Table 3. Assessment Formats Commonly used by Mathematics Teachers $(\mathrm{N}=15)$

\begin{tabular}{lcc}
\hline Assessment Format & Mean & Std. dev. \\
\hline Essay type & 3.47 & 0.74 \\
Multiple choice & 2.27 & 0.59 \\
True/false & 1.53 & 0.74 \\
Matching items & 1.67 & 0.62 \\
Completion items & 1.80 & 0.77 \\
\hline Average scores & 2.15 & 0.69
\end{tabular}

Mean Range: not used (0.4-1.4), used occasionally (1.5-2.4), used often (2.5-3.4); used very often (3.5-4.4).

The average mean scores $(\mathrm{M}=2.15, \mathrm{SD}=.69)$ as shown in Table 3 indicate respondents' agreement that the listed assessment format are used by mathematics teachers in the OLA circuit occasionally. Table 3, further indicates that essay type questions were used very often $(\mathrm{M}=3.47$, $\mathrm{SD}=0.74)$ while the rest of the formats, thus multiple choice $(\mathrm{M}=2.27, \mathrm{SD}=0.59)$, true/false $(\mathrm{M}=1.53, \mathrm{SD}=0.74)$, matching items $(\mathrm{M}=1.67, \mathrm{SD}=0.62)$ and completion items $(\mathrm{M}=1.80$, $\mathrm{SD}=0.77$ ) were all used occasionally'. During the interview, most of the teachers acknowledged that both essay and multiple-choice type questions are prescribed for use at the junior high school level, but they (teachers) like using essay type questions since it easy to craft essay questions as compared to multiple choice questions.

Table 4, present summary of the analysis on student's opinion about assessment format commonly used by mathematics teachers. 
Table 4. Students' Views on their Teachers use of Assessment Formats $(\mathrm{N}=119)$

\begin{tabular}{lcc}
\hline Assessment Format & Mean & Std. dev. \\
\hline Essay type & 3.42 & 0.73 \\
Multiple choice & 2.37 & 0.78 \\
True/false & 1.66 & 0.92 \\
Matching items & 2.04 & 0.85 \\
Completion items & 2.20 & 0.87 \\
\hline Average scores & 2.34 & 0.83 \\
\hline
\end{tabular}

Mean Range: Not used (0.4-1.4), used occasionally (1.5-2.4), used often (2.5-3.4); used very often (3.5 - 4.4).

From Table 4, the average mean score and standard deviation were 2.34 and 0.83 respectively. This means that the students generally viewed the named assessment formats as 'used occasionally'. Generally, this is a confirmation of the views expressed by the mathematics teachers in Table 3. Also, a critical study of the individual items reveals similar trends as the views of the teachers in Table 5 and in the interview.

\subsection{Assessment Feedback Practices of Mathematics Teachers}

Research question three sought to solicit responses from both teachers and students about the promptness of teachers when it comes to providing assessment feedback and how they do it. Summary of the analysis is shown in Table 5.

Table 5. Teachers' Views on Assessment Feedback Practices ( $\mathrm{N}=15)$

\begin{tabular}{lcc}
\hline Feedback Practice & Mean & Std.dev \\
\hline I mark students work and quickly gives it back to them & 3.13 & 0.52 \\
I revise assessment task with my students & 3.20 & 0.68 \\
I rank my students test results & 2.23 & 0.83 \\
I motivate students who perform well in Mathematics & 2.60 & 0.82 \\
I provide written comments along with students' marks & 3.20 & 0.68 \\
I point out my students' weaknesses to them & 3.13 & 0.64 \\
I talk to students about how they can improve their Performance & 2.73 & 0.80 \\
I organize remedial teaching for those who get low marks & 1.67 & 0.72 \\
I use assessment results to provide guidance to my students & 2.53 & 0.64 \\
\hline Average scores & 2.72 & 0.67 \\
\hline
\end{tabular}

Mean Range: Never $(0.4-1.4)$, sometimes $(1.5-2.4)$, most of the times $(2.5-3.4)$; always $(3.5-4.4)$.

The average mean score and standard deviation in Table 5 were 2.72 and 0.67 respectively. This generally means that the teachers 'most of the time' carry out the stated feedback practices in their schools. For instance, the individual item analysis on Table 5 further shows that the teachers most of the time mark their students work $(\mathrm{M}=3.13, \mathrm{SD}=0.52)$ and revise assessment task with them $(M=3.20, S D=0.68)$. Similarly, the results show that the teachers most of the time provide written comments along with students' marks $(\mathrm{M}=3.20, \mathrm{SD}=0.68)$, and point out students' weaknesses to them $(\mathrm{M}=3.13, \mathrm{SD}=0.64)$.

During the interview, most of the teachers asserted that they regularly mark and revise their students work with them. This shows the efforts made by the teacher in using assessment to help students know their learning progress. The teachers interviewed admitted that they do not rank students test results except the end of term exams.

Table 6 provides summary of the analysis about students' views on assessment feedback practices of mathematics teachers. 
Table 6. Students' Opinion on Assessment Feedback Practices of Mathematics Teachers (N=119)

\begin{tabular}{lcc}
\hline Feedback Practice & Mean & Std.dev \\
\hline Teacher marks our work and gives it back quickly & 2.96 & 0.75 \\
Teacher revises assessment task with us & 2.63 & 0.86 \\
Teacher ranks our test results & 2.34 & 0.47 \\
Teacher motivates students who perform well in mathematics & 2.53 & 0.64 \\
Teacher provides written comments along our marks & 2.92 & 0.77 \\
Teacher points our weaknesses to us & 2.61 & 0.70 \\
Teacher talks to us about how we can improve our Performance & 2.62 & 0.75 \\
Teacher organizes remedial teaching for those who get low marks & 1.72 & 0.97 \\
Teacher uses assessment results to provide guidance to us & 2.53 & 0.64 \\
\hline Average scores & 2.55 & 0.84 \\
\hline
\end{tabular}

Mean Range: Never $(0.4-1.4)$, sometimes $(1.5-2.4)$, most of the times $(2.5-3.4)$; always $(3.5-4.4)$.

The average mean score and standard deviation of Table 6 were 2.55 and 0.84 . This means that the stated feedback practices 'most of the time' were carried out in the schools. This clearly confirms the views expressed by the teachers about the occurrence of the stated assessment feedback practices as contained in Table 5 and in the interview.

\subsection{Impacts of Assessment on Mathematics Instruction}

Research question four was intended to find out the perceived impact of assessment practices on mathematics instruction. Summary of the teachers' responses is presented in Table 7.

Table 7. Teachers' Views on the Impacts of Assessment on Mathematics Instruction $(\mathrm{N}=15)$

\begin{tabular}{lcc}
\hline Impacts of Assessment & Mean & Std. dev \\
\hline It helps me to identify and improve the weaknesses of my students & 3.47 & 0.64 \\
It develops my students' confidence in mathematics & 3.07 & 0.46 \\
It develops my students' interest in mathematics & 3.20 & 0.56 \\
It helps me to monitor my students learning progress & 3.60 & 0.51 \\
It helps me to involve my students in my lessons & 3.53 & 0.52 \\
It helps me to identify students who need special attention in & 3.32 & 0.59 \\
learning mathematics & & \\
It helps me to know if my lesson objectives are being achieved & 3.53 & 0.64 \\
It helps me in putting my students into appropriate learning groups & 3.27 & 0.59 \\
\hline Average scores & 3.37 & 0.56 \\
\hline
\end{tabular}

Mean Range: Strongly disagree $(0.4-1.4)$, disagree $(1.5-2.4)$, agree $(2.5-3.4)$; strongly agree $(3.5-4.4)$.

The average mean score and standard deviation of Table 7, being 3.37 and 0.56 respectively indicate that the teachers generally 'agreed' that assessment has an impact on mathematics instruction. A critical study of the individual statements show that the teachers strongly agreed that assessment helps them to identify and improve the weaknesses of their students $(M=3.47$, $\mathrm{SD}=0.64)$. Also, the teachers agreed that assessment develops students' confidence in mathematics $(\mathrm{M}=3.07, \mathrm{SD}=0.46)$, and it develops students' interest in mathematics $(\mathrm{M}=3.20$, $\mathrm{SD}=0.56)$. Again, the results revealed that the teachers strongly agreed that assessment helps them to monitor their students learning progress $(\mathrm{M}=3.60, \mathrm{SD}=0.51)$, and to involve their students in their lessons $(\mathrm{M}=3.53, \mathrm{SD}=0.52)$. Furthermore, Table 7 shows that the teachers agreed that with assessment, they were able to identify students who need special attention $(\mathrm{M}=3.32, \mathrm{SD}=0.59)$. The teachers also strongly agreed $(\mathrm{M}=3.53, \mathrm{SD}=0.64)$ that through assessment they were able to know if their lesson objectives were achieved. In the interview, many of the teachers acknowledged that assessment actually impact teaching and learning of mathematics. Two teachers commented: 
Assessment helps me to know if my lesson was well taught and to know the next thing to do. [Teacher 'D']

With assessment, I am able to collect information that enable me make decisions about my students learning progress and my own teaching strategies. [Teacher ' $C$ ']

Table 8 shows the summary of analysis concerning students views about impact of assessment on students learning.

Table 8. Students' Views on the impact of assessment $(\mathrm{N}=119)$

\begin{tabular}{lll}
\hline Impact of Assessment & Mean & Std. dev \\
\hline It helps me to identify and improve my weaknesses & 3.53 & 0.70 \\
It develops my confidence in mathematics & 2.82 & 1.03 \\
It develops my interest in learning mathematics & 2.87 & 0.99 \\
It helps me to monitor my learning progress & 3.23 & 0.73 \\
It helps me to know what to learn & 3.54 & 0.74 \\
\hline Average scores & 3.20 & 0.84 \\
\hline Mean Range: Strongly disagree $(0.4-1.4)$, disagree $(1.5-2.4)$, agree $(2.5-3.4) ;$ strongly agree $(3.5-4.4)$.
\end{tabular}

The average mean score $(\mathrm{M}=3.20, \mathrm{SD}=.84)$ as shown by Table 8 implies that the students largely agree with the teachers on the statements about the role assessment plays on teaching and learning of mathematics in their schools. For instance, Table 8 shows that the students strongly agree that through assessment they were able to identify and improve their weaknesses in mathematics $(\mathrm{M}=3.53, \mathrm{SD}=0.70)$. The students' views largely confirm the views of the teachers as presented in Table 7 and in the interview.

\subsection{Challenges Associated with Implementation of Assessment Procedures}

The last research question sought to find out the challenges that the teachers perceive to be hindering the quality of assessment of students in mathematics in their schools. Details of the challenges are shown in Table 9.

Table 9. Teachers' Perceived Challenges that constrain Quality Assessment Practices in Mathematics $(\mathrm{N}=15)$

\begin{tabular}{lll}
\hline Challenge & Mean & Std. dev \\
\hline The school has inadequate assessment materials & 3.07 & 0.46 \\
Assessment increase my workload & 3.13 & 0.64 \\
Assessment takes much of my time & 3.13 & 0.64 \\
I do not have adequate skills on assessment in mathematics & 3.20 & 0.56 \\
Some of my students do not submit their work for marking & 3.07 & 0.59 \\
My students' attendance to school is poor & 3.13 & 0.74 \\
\hline Average scores & 3.12 & 0.61
\end{tabular}

Mean Range: Strongly disagree $(0.4-1.4)$, disagree $(1.5-2.4)$, agree $(2.5-3.4)$; strongly agree $(3.5-4.4)$

As shown in Table 9, the average mean score and standard deviation were 3.12 and 0.61 respectively. This indicates that the teachers largely 'agree' to the statements about the challenges that constrain quality assessment in mathematics in their schools. A study of the individual statements revealed that the teachers agree that their schools had inadequate assessment materials $(\mathrm{M}=3.07, \mathrm{SD}=0.46)$, and assessment increases their workload $(\mathrm{M}=3.13$, $\mathrm{SD}=0.64$ ). Similarly, the results of Table 9 shows that the teachers agree with the assertions that they (the teachers) do not have adequate skills for assessing students in mathematics $(\mathrm{M}=3.20, \mathrm{SD}=0.56)$, and some students do not submit their work for marking $(\mathrm{M}=3.07$, $\mathrm{SD}=0.59)$. 
The information gathered through the interview conducted largely confirmed the results of the questionnaire. For instance, in the interview, most of the teachers reported inadequate materials for assessment, increase workload as well as failure of some students to submit their assessment task for marking due to poor attendance to school as some of the challenges to quality assessment practices in their schools. Here, the non-availability of materials such as SBA books, report cards, graph sheets and answer booklets greatly affected the assessment practice that were being carried out in these schools.

On the issue of increased workload, many of the teachers also complained that the mathematics syllabus is loaded besides they teach other subjects in addition to the mathematics. These suggest that the high workload makes them to pay less attention to assessment of their students learning. One of the teachers commented;

The teaching alone takes all my time and I will not be able to finish the syllabus if I am to engage in effective assessment practices like organizing remedial lessons for students who normally get low marks. [Teacher 'A']

\section{DISCUSSION}

The study revealed that teachers often use variety of assessment modes in the classroom to assess students' progress in mathematics. The modes include class exercise, homework and trial work. However, when it comes the use of group work and project work, the teachers indicated that they do not use it at all. It is more likely that the teachers sideline of project work and group work might be as a result of lack of proper understanding of the usefulness of these methods or probably insufficient instructional time at their disposal. This practice actually deviates from CRDD (2011) directive that the performance of students in mathematics can best be assessed if the assessment is made on different test modes including projects, mental exercises, group exercises (cooperative learning exercises) and other practical activities. The present study discovery of the use of varied assessment procedures is in line with the findings of Kipkorir (2015) who discovered that mathematics teachers in the Nandi Central Sub-County, Kenya, have used multiple methods of assessment such as discourse, observation, students' selfassessment and peer assessment which have had massive turns on students learning of concepts in mathematics. Equally, other studies have also shown enormous significance of "varied assessment modes in students learning (Birgin, 2011; Buhagiar, 2007).

Most teachers and the students agreed that essay type questions were the predominantly used assessment format. In an interview section with some of the teachers, they explained that, they often times use essay type of test because, it is easy to construct. It is known in literature that ideally, the purpose of the test, the difficulty level that the teacher anticipates and the characteristics of the test takers inform the appropriate format to use. In a situation whereby, teachers resort to just a particular test format because they perceive it to be easier when constructing such test, then it is more likely that the teachers lack adequate competencies in test construction. This result is in line with Quansah, Amoako and Ankomah (2018) who discovered that teachers in the Cape Coast Metropolis have limited skills in the construction of test items. Moreover, it could be possibly due to the fact that teachers have poor attitude when it comes to test construction and hence overreliance to a particular test format (Quansah \& Amoako, 2018).

The study showed that teachers 'most of the time' carry out the stated feedback practices in their schools. This was actually corroborated by the responses of students on the questionnaire. However, there were few areas that teachers indicated that they normally do not get time to organize remedial classes for students as part of the feedback exercise. This excuse from the teachers might have been born out of the fact that they see feedback exercise as distinct from the teaching and learning encounter. This confirms the assertion made by Taras (2003) that the challenges with feedback are that teachers and students see feedback in isolation from other 
aspects of the teaching and learning process, and considers feedback to be primarily a teacherowned endeavour.

It was evident from the results of the study that teachers and students alike perceive assessment as having impact on mathematics instruction. On the part of the teachers, they believe that assessment helps them to know of the lesson was well taught. It also helps them to know the weakness of the students. Students also use the assessment results to gauge their understanding of concepts taught by the teachers in class. This study finding as shown corroborates several other study findings in the literature. For example, Black and William (2010) that teachers can interpret and use assessment results to gauge whether the teaching has been successful in achieving its objective(s). Black and William added that the teacher may then use assessment results as the basis for giving advice on students learning or reviewing teaching. Again, KoloiKeaikitse (2012) found that in order for teachers to diagnose students' needs, design and implement instructional interventions, evaluate students work, and assign grades, they (teachers) need continuous access to evidence of students learning arising from high-quality classroom assessment practices. In the context of classroom instruction, formative assessment practices help students to know whether they have understood the concept taught by the teacher or not, this serve a motivational role for extra effort on the part of the student (Amoako, 2018).

Finally, the study discovered some challenges that frustrate classroom assessment practices to include; inadequate assessment materials, high workload of teachers and poor attendance of students to school among other minor ones. The teachers' views are in line with the opinion of Tamakloe, Amedahe, and Attah (1996) that assessment especially continuous assessment is time consuming as teachers have to construct their assessment tasks, administer them, grade the scores, have the scores recorded and then carry out revision with the students. Tamakloe, Amedahe and Attah added that assessment increases the workload of teachers.

\section{CONCLUSION}

Based on the findings of the study it can be concluded that mathematics teachers in junior high schools of OLA Circuit tend to use more of class test, homework and trial work in assessing students learning to the neglect of group work and project work. This situation is more likely to deny students the benefits of knowledge sharing (learning from peers), in this case teaching and learning of mathematics would be done in abstract.

Again, it can be concluded that there is undue emphasis on the use of essay type questions in the schools which make it difficult to adequately prepare the students for the BECE in which essay questions and objectives/multiple choice questions are weighed equally. Moreover, assessment practices have an impact on classroom mathematics instruction which ranges from promoting involvement of students in mathematics lessons to increasing teachers' pedagogical effectiveness. Assessment is therefore a powerful tool for enhancing effective teaching and learning of mathematics.

Finally, despite the generally acclaimed benefits of assessment, certain challenges such as inadequate assessment materials, high workload of teachers and poor attendance of students to school tend to frustrate the positive impact of assessment on the teaching and learning of mathematics. Based on the findings from the study, it is recommended that Head teachers should ensure that as part of the school base assessment (SBA) procedures, teachers' pay particular attention to project work and group work. These procedures have the tendency to encourage peer tutoring among students which augment classroom instruction. In addition, head teachers could collaborate with the GES to organize regular in-service programmes for the mathematics teachers to constantly update their knowledge, skills and attitudes toward assessment. Head teachers and the teachers also need to liaise with the educational authorities and philanthropist to provide material necessary for assessment practices in the various schools. 


\section{ORCID}

Isaac Buabeng (iD) https://orcid.org/0000-0003-4569-087X

\section{REFERENCES}

Amoako, I. (2018). Formative assessment practices among distance education tutors in Ghana. African Journal of Teacher Education, 7(3), 22-36.

Asamoah-Gyimah, K. \& Duodu, F. (2007). Introduction to research methods in education. Winneba: The Institute of Educational Development and Extension, University of Education, Winneba.

Birgin, O. (2011). Pre-service mathematics teachers' views on the use of portfolios in their education as an alternative assessment method. Educational Research and Reviews, 6(11), 710-721.

Black, P., Harrison, C., Lee, C., Marshall, B., \& Wiliam, D. (2010). Assessment for learning, putting it into practice. London: Open University Press.

Buhagiar, M. A. (2007) Classroom assessment within the alternative assessment paradigm: revisiting the territory. Curriculum Journal, 18(1), 39 - 56.

Cape Coast Metropolitan Education Directorate (2010). Analysis of 2010 basic education certificate examination results. Cape Coast.

Cape Coast Metropolitan Education Directorate (2012). Analysis of 2012 basic education certificate examination results. Cape Coast.

Cape Coast Metropolitan Education Directorate (2014). Analysis of 2014 basic education certificate examination results. Cape Coast.

Curriculum Research and Development Division (2012). National syllabus for mathematics: Junior high school 1- 3. Accra: Ministry of Education.

Curriculum Research and Development Division (2011). Teachers hand book on school-based assessment for junior high schools (Mathematic). Accra: Ministry of Education.

Dillard, J. (2013). Five most important methods for statistical data analysis. Retrieved, from http://www.bigskyassociates.com/blog/bid/356764/5-Most-Methods-ForStatisticalDataAnalsis

Holt, L.C., \& Kysilka, M. (2006). Instructional patterns: Strategies for maximizing students learning. California: Sage Publication, Inc.

Kipkorir, K. E. (2015). Classroom assessment practices by mathematics teachers in secondary schools of Kenya. Unpublished Masters thesis, University of Nairobi, Kenya.

Larry, H. C., \& Kysilka, M. (2006). Instructional patterns: Strategies for maximizing students' learning. California: Sage Publication, Inc.

Ornstein, A. C., \& Lasley, T. J. (2000). Strategies for effective teaching. United States of America: The McGraw Company Inc.

Quansah, F. (2017). The use of Cronbach alpha reliability estimate in research among students in public universities in Ghana. African Journal of Teacher Education, 6(1), 56-64.

Quansah, F., Amoako, I., \& Ankomah, F. (2018). Teachers' Test Construction Skills in Senior High Schools in Ghana: Document Analysis. International Journal of Assessment Tools in Education, 6(1), 1-8.

Salaria, N. (2012). Meaning of the term descriptive survey research method. International Journal of Transformations in Business Management,1(6), Apr-Jun. Retrieved from http://ijtbm.com/images/short_pdf/Apr_2012_NEERU\%2520SALARIA\%25202.pdf.

West African Examination Council (2013). Basic education certificate examination: Chief examiners' report. Accra: West African Examination council.

Quansah, F., Amoako, I. (2018). Attitude of Senior High School (SHS) teachers towards test construction: Developing and validating a standardized instrument. Research on Humanities and Social Sciences, 8(1), 25-30. 
Sarantakos, S. (2005). Social research (3rd ed.). New York: Palgrave Macmillan

Tamakloe, E. K., Amedahe, F. K., \& Attah, E. T. (1996). Principles and methods of teaching. Accra: Black Mask Ltd.

Taras, M. (2003). To feedback or not to feedback in student self-assessment. Assessment and Evaluation in Higher Education, 28(5), 549- 565. 